\title{
ORIGINAL
}

\section{WEIGHT OF CALCANEUM AND TALUS FOR DETERMINATION OF SEX}

\author{
DR. IMRAN AHMAD, MBBS, M.Phil \\ Associate Professor of Anatomy, \\ Quaid-e-Azam Medical College, \\ Bahawalpur.
}

DR. NABILA KAUKAB, MBBS, M.Phil.

Associate Professor of Anatomy,

Faculty of Health Sciences,

University of Faisalabad, Faisalabad.

\begin{abstract}
Introduction: Talus \& Calcaneum are involved in the transmission of body weight to the ground, considerable variation in the morphological features and weight of these bones have been reported by various authors. Objectives: To determine the importance of bone weight as a discriminative factor in identification of sex. Material and Method: 198 calcanei and 150 tali from Anatomy department of Quaid-e-Azam Medical College Bahawalpur were selected for the study. Mean weight of male \& female bones on right \& left side were determined. To increase the efficacy of the results they were statistically reevaluated by applying $\pm 3 S D$ and determining a calculated range. From this range, D.P. or demarcating points were established. Results: Bones of the right side were found to be heavier than those of the left side; also the mean weights of the male bones were greater than those of the female bones. On applying D.P.s it was possible to identify sex with greater accuracy than with other metrical criteria. Conclusion: These findings suggest that weight of tarsal bones is a useful metrical feature for sex determination.
\end{abstract}

Key Words: Calcaneum, Talus, Identification points (I.P.), Demarcating points(D.P.), Bicondylar width, Metrical criteria.

\section{INTRODUCTION}

The importance of sex determination from available skeleton is well recognized in medico legal work. Sex determination from individual bones is a difficult task but several workers have attempted to do so using various morphological features. Even when entire bony pelvis and skull are available no more than $90-95 \%$ accuracy can be achieved ${ }^{16}$. A number of studies have been carried out to identify sex through morphological features of bones such as measurement of femoral head $^{4,11,12,13,15,24,30}$, length \& curvature of femoral shaft, bicondylar width, trochanteric length, and mid circumference of the shaft ${ }^{28,30}$. Morphological features of other bones such as Sacrum ${ }^{3,5,31}$, Pelvis ${ }^{6}$, Sternum ${ }^{2,20,21}$, Clavicle $^{14,22,29}$, Scapula ${ }^{9}$ and Mandible ${ }^{7,17}$ have also been studied to identify sex. 
Talus is the link between foot \& leg and is involved in the formation of ankle sub talar and talocalcaneonavicular joints ${ }^{32}$. Calcaneum is the largest and the strongest of the tarsal bones, it transmits body weight from the talus to the ground. It articulates with the talus superiorly and cuboid anteriorly.

Its shelf like projection sustentaculum tali supports the talar head, the articular facets on the sustentaculum tali show regional and racial variation ${ }^{18,19}$. Bone weight in foot is stable between $19-40$ years of age. Time environment $\&$ heat has minimal effect on the bones ${ }^{27}$. Ageing process occurs in the foot bones as well but is more evident in metatarsal \& the phalanges as compared to the tarsal bones ${ }^{16}$.

Identification of sex based on morphological features is not very reliable because of subjective assessment of the observer and these methods have been replaced by metrical ones ${ }^{8,10,21,28}$. Identification of sex by weight have been carried out for femur ${ }^{25}$, Clavicle $^{14,22}$, Humerus ${ }^{23}$ and Tarsal bones $^{26}$.The present study attempts to establish the value of weight of the calcaneum \& talus as a criterion for discriminating sexual dimorphism in Pakistan.

\section{MATERIAL AND METHOD}

198 calcanei ( 126 males \& 72 females) and 150 tali (96 males \& 54 females) were selected for study from cadavers between 20-40 years of age. Bones with any pathological lesions or showing any signs of crumbling were discarded. The study was carried out on bones from cadavers obtained from Anatomy Department of Quaid-e-Azam Medical College, Bahawalpur from 1995$--2004$.

The bones were prepared by removing any excess soft tissue, boiling them in water for two hours, cleaning with soap water and a soft brush. The cleaned bones were dried under shade and weighed on electric scale (Sartorius GM 5n GOTTINGEN Made in Germany).

The actual range and mean weight for right and left male and female calcanei were established. Identification points or I.P. were determined by noting the minimum and maximum limits for corresponding bones in males and females i.e. the I.P for right male calcaneum was the highest weight recorded for the right female calcaneum, while the I.P for right female calcaneum was the lowest weight recorded for right male calcaneum. All bones weighing more than the determined I.P for males were identified as males and all bones weighing less than the determined I.P for females were identified as females ${ }^{26}$.

In medico legal practice identification of sex with $100 \%$ accuracy is required and identification points (I.P) thus established may not be applicable to other data even from the same region. To make the results more accurate a calculated range was determined by adding and subtracting $\pm 3 S D$ to and from the mean value of each measurement (which would cover $99.75 \%$ of the sample).

The maximum and minimum weights in the calculated range were taken as demarcating points or D.P. for corresponding bones of the opposite sex i.e. the highest weight in the calculated range of the right female calcneum was taken as the D.P. for right male calcaneum and the lowest weight in the calculated range of right male calcaneum was the demarcating point for right female calcaneum ${ }^{26}$. Student " $\mathrm{t}$ " test was used for comparison of means between the male and female bones.

\section{OBSERVATION}

The weight of right male calcaneum varied from $35.30 \mathrm{gms}--65 \mathrm{gm}$ with a mean of $52.91 \mathrm{gms}$. Where as the weight of left male calcaneum varied from $35 \mathrm{gms}$ $68.13 \mathrm{gm}$. with a mean of $47.72 \mathrm{gms} .92 \%$ of the right male calcanei were heavier than the left male calacanei ( Table I).

The right female calcaneum weighed from 31.46-37.90 $\mathrm{gm}$ ( mean weight of $35.18 \mathrm{gm}$ ) while the weight of left female calcaneum varied from 28.60-37.05gms (mean $34.7 \mathrm{gms}$ ). In $87 \%$ of the cases right female calcaneum was heavier than its counterpart on the left side (Table I). 


\begin{tabular}{|c|c|c|c|c|}
\hline \multicolumn{4}{|c|}{ Table I. Measurement of weight in gm. of Calcanei (n=198) } \\
\hline $\begin{array}{c}\text { Details of } \\
\text { Measurement }\end{array}$ & \multicolumn{2}{|c|}{ Male } & \multicolumn{2}{c|}{ Female } \\
\cline { 2 - 5 } & Right & Left & Right & Left \\
\hline Number & 63 & 63 & 37 & 35 \\
\hline Mean & 52.91 & 47.72 & 35.18 & 34.70 \\
\hline Actual range & $35.30-$ & $35.00-$ & $31.46-$ & $28.60-$ \\
\hline I.P & 75.00 & 68.13 & 37.90 & 37.05 \\
\hline $\begin{array}{c}\text { \% of bones } \\
\text { weighing } \\
\text { beyond I.P. }\end{array}$ & $96.08 \%$ & $92 \%$ & $47.02 \%$ & $44.04 \%$ \\
\hline
\end{tabular}

\begin{tabular}{|c|c|c|c|c|}
\hline \multicolumn{4}{|c|}{ Table II. Statistical Calculation of weight in gm. of Calcanei } \\
(n=198)
\end{tabular}

$96.8 \%$ of the right $\& 92 \%$ of the left male calcanei were heavier than the heaviest of the female calcaneum of the corresponding side with an IP of $>37.90 \mathrm{gm}$ for right side and an IP of $>37.05 \mathrm{gm}$ for the left side( the max. weight for right and left female calcanei). The IP for female calcanei were $<35.30 \mathrm{gm}$ for right $\&<35.00 \mathrm{gm}$ for left side ( $m$ in values for right \& left male calcanei). Sexual determination using these I.P could only be made in $47.2 \%$ of the cases on right and $44.4 \%$ cases on the left side, i.e. $47.2 \%$ of the right $\& 44.4 \%$ of the left female calcanei were lighter than the lightest of the male bones

(Table I) .

\begin{tabular}{|c|c|c|c|c|}
\hline \multirow{2}{*}{ Table III. Measurement of weight in gm of Tali ( $\mathrm{n=150}$ ) } \\
\hline $\begin{array}{c}\text { Details of } \\
\text { Measurement }\end{array}$ & \multicolumn{2}{|c|}{ Male } & \multicolumn{2}{c|}{ Female } \\
\cline { 2 - 5 } & Right & Left & Right & Left \\
\hline Number & 52 & 44 & 24 & 30 \\
\hline Mean & 29.23 & 28.76 & 22.25 & 22.15 \\
\hline Actual range & $22.40-$ & $22.20-$ & $20.99-$ & $20.49-$ \\
\hline I.P. & 34.20 & 36.98 & 23.50 & 23.11 \\
\hline $\begin{array}{c}\text { \% of bones } \\
\text { weighing } \\
\text { beyond I.P. }\end{array}$ & $85.7 \%$ & $85.7 \%$ & $61 \%$ & $50 \%$ \\
\hline
\end{tabular}

After applying D.P.' sex could still be established in $96.8 \%$ of the right and $90 \%$ of the left male calcanei, whereas for female calcanei, the percentage of identifiable bones fell to $0 \%$ on both right and left sides (Table II).

\begin{tabular}{|c|c|c|c|c|}
\hline \multicolumn{5}{|c|}{ Table IV. Statistical Calculation of weight in gm of Tali $(n=150)$} \\
\hline \multirow{2}{*}{$\begin{array}{c}\text { Details of } \\
\text { Measurement }\end{array}$} & \multicolumn{2}{|c|}{ Male } & \multicolumn{2}{|c|}{ Female } \\
\hline & Right & Left & Right & Left \\
\hline Number & 52 & 44 & 24 & 30 \\
\hline Mean & 29.23 & 28.76 & 22.55 & 22.15 \\
\hline $\begin{array}{l}\text { Standard } \\
\text { Deviation }\end{array}$ & 3.68 & 4.45 & 0.68 & 0.71 \\
\hline $\begin{array}{l}\text { Calculated } \\
\text { range }\end{array}$ & $\begin{array}{l}18.18- \\
40.28\end{array}$ & $\begin{array}{l}15.41- \\
42.11\end{array}$ & $\begin{array}{l}20.49- \\
24.61\end{array}$ & $\begin{array}{l}20.02- \\
24.28\end{array}$ \\
\hline D.P. & $>24.61$ & $>24.28$ & $<18.18$ & $<15.41$ \\
\hline $\begin{array}{c}\% \text { of bones } \\
\text { weighing } \\
\text { beyond I.P. }\end{array}$ & $85.7 \%$ & $71.4 \%$ & $0 \%$ & $0 \%$ \\
\hline & & & fh th & \\
\hline
\end{tabular}

The weight \& mean range for right \& left male tali (96) were 22.40--34.20 gm (mean $29.23 \mathrm{gm}$ ) \& 22.20 -36.98 gm. (mean $28.76 \mathrm{gm}$ ) respectively. $78.6 \%$ of the right male tali were heavier than the corresponding bones on 
the left side. In females the weight \& range of right and left sided tali (54) were 20.99-23.50 gm (mean $22.55 \mathrm{gm}$ ) \& 20.49--23.11gm. (mean $22.15 \mathrm{gm}$ ) respectively. $97 \%$ of the right female tali were heavier than the left female tali ( Table III).

\begin{tabular}{|c|c|c|c|c|}
\hline \multicolumn{4}{|c|}{ Table V. Comparison of Identifiable male calcaneum with the } \\
Study of Singh \& Singh;
\end{tabular}

The I.P. for right \& left male tali was $>23.50 \mathrm{gms}$. \& $>23.11 \mathrm{gm}$ respectively. For female tali the I.P were $<22.40 \mathrm{gm}$. on the right \& $<22.20 \mathrm{gm}$. on the left sides. By using these I.P, it was possible to identify sex in $85.7 \%$ of the right and left male tali. While for female tali the percentage of identifiable bones using the I.P was $61 . \%$ on right and $50 \%$ on the left side ( Table III).

Table VI. Comparison of Identifiable Female calcaneum with the Study of Singh \& Singh;

\begin{tabular}{|c|c|c|c|c|}
\hline \multirow{2}{*}{$\begin{array}{c}\text { Details of } \\
\text { Measurement }\end{array}$} & \multicolumn{2}{|c|}{ Present Study } & \multicolumn{2}{c|}{ Singh \& Singh } \\
\cline { 2 - 5 } & Right & Left & Right & Left \\
\hline Mean & 35.18 & 34.70 & 25.01 & 24.25 \\
\hline I.P. & $<35.30$ & $<35$ & $<23.3$ & $<23.7$ \\
\hline $\begin{array}{c}\% \text { of bones } \\
\text { weighing < I.P }\end{array}$ & $47.2 \%$ & $44.4 \%$ & $40 \%$ & $28 \%$ \\
\hline $\begin{array}{c}\text { D.P. } \\
\text { \% of bones } \\
\text { weighing < D.P. }\end{array}$ & $<\%$ & $0 \%$ & $0 \%$ & $0 \%$ \\
\hline
\end{tabular}

For male and female tali D.P. were calculated in the same manner as for the calcanei Whereas in male tali the percentages of the identifiable bones remained $85.7 \%$ on the right and was slightly reduced to $71.4 \%$ on the left side even after applying D.P, it fell to $0 \%$ in females on both right \& left sides (Table IV).

Table VII. Comparison of Identifiable male Tali with the Study of Singh \&Singh;

\begin{tabular}{|c|c|c|c|c|}
\hline \multirow{2}{*}{$\begin{array}{c}\text { Details of } \\
\text { Measurement }\end{array}$} & \multicolumn{2}{|c|}{ Present Study } & \multicolumn{2}{c|}{ Singh \& Singh } \\
\cline { 2 - 5 } & Right & Left & Right & Left \\
\hline Mean & 29.23 & 28.76 & 24.06 & 23.09 \\
\hline I.P. & $>23.50$ & $>23.11$ & $>20.5$ & $>20.0$ \\
\hline $\begin{array}{c}\text { \% of bones } \\
\text { weighing > I.P }\end{array}$ & $85.7 \%$ & $85.7 \%$ & $77 \%$ & $42 \%$ \\
\hline $\begin{array}{c}\text { D.P. } \\
\text { \% of bones } \\
\text { weighing > D.P. }\end{array}$ & $85.7 \%$ & $71.4 \%$ & $28 \%$ & $32 \%$ \\
\hline
\end{tabular}

Table VIII. Comparison of Identifiable Female Tali with the Study of Singh \& Singh;

\begin{tabular}{|c|c|c|c|c|}
\hline \multirow{2}{*}{$\begin{array}{c}\text { Details of } \\
\text { Measurement }\end{array}$} & \multicolumn{2}{|c|}{ Present Study } & \multicolumn{2}{c|}{ Singh \& Singh } \\
\cline { 2 - 5 } & Right & Left & Right & Left \\
\hline Mean & 22.55 & 22.15 & 15.66 & 15.03 \\
\hline I.P. & $<22.40$ & $<22.20$ & $<15.1$ & $<15.2$ \\
\hline $\begin{array}{c}\text { \% of bones } \\
\text { weighing < I.P }\end{array}$ & $61 \%$ & $50 \%$ & $46 \%$ & $42 \%$ \\
\hline $\begin{array}{c}\text { D.P. } \\
\text { \% of bones } \\
\text { weighing < D.P. }\end{array}$ & 018.18 & $<15.41$ & $<9.36$ & $<8.27$ \\
\hline
\end{tabular}

\section{DISCUSSION}

The value of weight in discriminating sexual dimorphism has not been studied in Pakistani population, although some studies have been carried out in other parts of the world. The present study on the weights of calcaneum \& talus provides us information on the sexual differences in the weight of these bones and tries to establish the importance of weight as a criterion for sex determination. The percentage of Calcanei \& Tali sexed by identification points (I.P.), when their efficiency was tested on the 
sample itself was quite high compared to the study of Singh \& Singh ${ }^{23}$. In the present study the percentages of identified right \& left male calcanei using I.P were $96.8 \% \& 90 \%$ respectively whereas in the study carried out by Singh \& Singh the percentages of identifiable bones using I.P. were $63 \%$ \& $57 \%$ only. Even after statistical calculations i.e. on applying D.P. these values remained the same ( $96.8 \%$ for right $\& 90 \%$ for left side) while in the study of Singh \& Singh the percentage of identifiable bones fell by more than $50 \%$ ( $24 \%$ on the right $\& 28 \%$ on the left side) (Table V).

In case of female calcanei the percentages of identifiable bones with I.P. were $47.2 \& 44.4 \%$ for right \& left side respectively, these values were comparable to those cited by Singh \& Singh ${ }^{26}$ and on applying D.P. they fell to $0 \%$ in both the studies (Table VI).

For male tali the percentages of identifiable bones using I.P were $85.7 \%$ for both right \& left sides, as compared to $77 \%$ \& $42 \%$ reported by Singh \& Singh. In the present study, the percentages of identifiable bones remained the same on the right side $(85.7 \%)$ with only a slight reduction on the left side $(71.4 \%)$ as compared to a significant reduction in the study of Singh \& Singh ${ }^{26}$. Where the percentages of identifiable bones fell from $63 \%$ to $24 \%$ on right and from $57 \%$ to $28 \%$ on the left side (Table VII).

In the present study percentage of identifiable female tali after applying D.P. fell markedly as compared to that reported by Singh \& $\operatorname{Singh}^{26}$ (from $22.40 \%$ on the right and $22.20 \%$ on the left side to $0 \%$ on both sides). Singh \& Singh have reported a reduction from $46 \%$ and $42 \%$ to $28 \%$ and $8 \%$ on the right and left sides (Table VIII).

There was no significant reduction in the number of identifiable male bones in present study, even after applying D.P. as compared to study of Singh \& Singh, this may be due to;

i Better nutritional status of our population.

ii Different dietary habits as people belonging to this part of the subcontinent have a higher intake of proteins and calcium as compared to their Indian counterparts who are strictly vegetarians.

The reduction however was significant and comparable for female bones in both studies probably due to poor nutritional status of women in both populations resulting from multiple childbirths and male dominance for food.

The differences between mean weights of male and female calcanei \& tali was statistically significant $P<.01$ which is different from the study of Singh \& Singh where the difference was $P<.001$ for both right and left side. The present observations suggest that weight is an important discriminative factor in identification of a significant percentage of male calcanei \& tali by using either I.P or D.P. Although a significant number of female bones could be identified using I.P. but on applying D. P. the percentage fell drastically

Our observations also indicate that there is a significant difference between the mean weights of bones of right \& left sides. $92 \%$ of the right male $\& 87 \%$ of the right female calcanei were heavier than those of the left side, while $78.6 \%$ of right male $\& 97 \%$ of the right female tali were heavier than those of the left side ( Table I \& III). These findings are similar to those reported by Ahmed et $\mathrm{al}^{1}$ who have also reported a right sided dominance.

\section{REFERENCES}

1. Ahmed R., RizviSIH. \& Rehman A. Weight of calcaneum in adult Pakistani Population. The Professional. 1997; 4(4): 353-355.

2. Ashley GT. The Human Sternum. The influence of sex and age on its measurements. J. forens. Med.1956; 3 : $27-43$.

3. Charnalia VM. Sex Differences and Sex Determinationin Human Sacra in South India. J. anat. Soc. India. 1967; 16: 33.

4. Dwight T. The Size of Articular surfaces of the Long Bones as Characteristic of Sex; an Anthropological study. Amer. J. Anat. 1905; 4: 19-32.

5. Fawcet E. The Sexing of Human Sacrum. J. Anat. Lond. 
1938; $72: 633$.

6. Genoves S. Revaluation of Age Stature and Sex of the Tepexpan remains, Mexico. Amer. J. phys. Anthrop. 1960; 18: 205-217.

7. Giles E. Sex Determination by Discriminant function Analysis of the Mandible. Amer. J. phys. Anthrop. 1964; 22: $129-136$.

8. Giles E. and Elliot $O$. Sex Determination by Discriminant function Analysis of the Crania. Amer. J. phys. Anthrop. 1963; 21: 53-68.

9. Hanihara K. Sexual Diagnosis of Japanese Long Bones by Means of Discriminant Function. J. anthrop. Soc. Japan 1958; 66: 187-196.

10. Hanihara K. Sex Diagnosis of Japanese Skull and Scapulae by Means of Discriminant Function. J. anthrop. Soc. Japan 1959; 67: 191-197.

11. Hasimoto M. Ethnologic studies on Chinese. J. Orient. Med.1938; 29: 32-34.

12. Holtby JRD. Some Indices and measurement of the Modern Femur. J. Anat. Lond. 1918; 52: 363-382.

13. Javedkar BS. A Study of Measurement of the Head of Femur with Special reference to Sex. A Preliminary Report. J. anat. Soc. India. 1961; 10: 25-27.

14. Jit I. and Singh S. The Sexing of Adult Clavicles. Indian. J. med. Res. 1966; 54: 551-571.

15. Kate BR. A Study of Regional Variations of the Indian Femur. The Diameter of the Head-its Medicolegal and Surgical Application. J. anat. Soc. India. 1964; 13: 8084.

16. Krogman WM. Race differences in the human skeleton: The human skeleton. Forensic medicine, $1^{\text {st }}$ ed. Charles C Thomas, Springfield. Illinois. USA. 224, 1962.

17. Martin ES. A Study pf Egyptian Series of Mandibles, with special reference to Mathematical Methods of Sexing. Biometrica 1936; 28: 149-178.

18. Moore KL. \& Dalley AF. Clinically oriented anatomy. 4th ed. Pp 515 Baltimore Lippincott Williams \& Wilkins. 1999.
19. Mughal IA., Aziz N., Din S. \& Rehman A. Human Calcaneum; variation in the articular facet of the sustetaculum tali. The Professional. 2001; 8(1): 90-93

20. Naryan D. and Varma HC. Sternal Index in U.P. Indian Males and Females. J. anat. Soc. India.1958; 7: 71-72.

21. Pons J. The sexual Diagnosis of Isolated Bones of the Skeleton. Human Biol. 1955; 27: 12-21.

22. Singh S. and Gangrade KC. The Sexing of Adult Clavicles. Verification and applicability of Demarcating Points. J. Indian Acad. Forens. Sci. 1968a; 7: $20-30$.

23. Singh S. and Singh SP. Identification of sex from the Humerus. Indian. J. med. Res. 1972a; 60: 1061-1066.

24. Singh SP. and Singh S. Identification of sex from the Head of the Femur. Demarcating Points for the Varnasai Zone. Indian med. Gaz. 1972b; 11: 45-49.

25. Singh S. and Singh SP. Weight of the femur- a useful measurement for identification of sex. Acta anat. 1974; 87: 141-145.

26. Singh S. and Singh SP. Identification of sex from tarsal bones. Acta anat. 1975; 93: 568-573.

27. Spitz WU. Identification of human remains: medicolegal investigation of death, 2 nd ed. Charles $C$ Thomas, Springfield Illinois USA. 57, 1980.

28. Steel FLD. The sexing of long bones with reference to the St. Bride,s series of identified skeleton. J. roy. Anthrop. Inst. 1962; 92: 212-222.

29. Terry RJ. The clavicle of the American Negro. Amer. J. phys. Anthrop. 1932; 16: 351-379.

30. Thieme FP. Sex in Negro skeletons. J. forens. Med. 1957; 4: 72-81.

31. Washburn SL. Sex differences in the pubic bones of Bantu and Bushman. Amer. J. of phys. Anthrop. 1949; 7 425-432.

32. Standring $S$ et all. Grays anatomy 39th ed. Pp 1512 Elsevier Churchill Living stone 2005. 